尽

SSCL-670

April 1994

Distribution Category: 400

L. Walling

T. Barts

E. Ruiz

W. Turner

N. Spayd

\title{
Above Cutoff Impedance Measurements of Pumping Holes for the Collider Liner
}

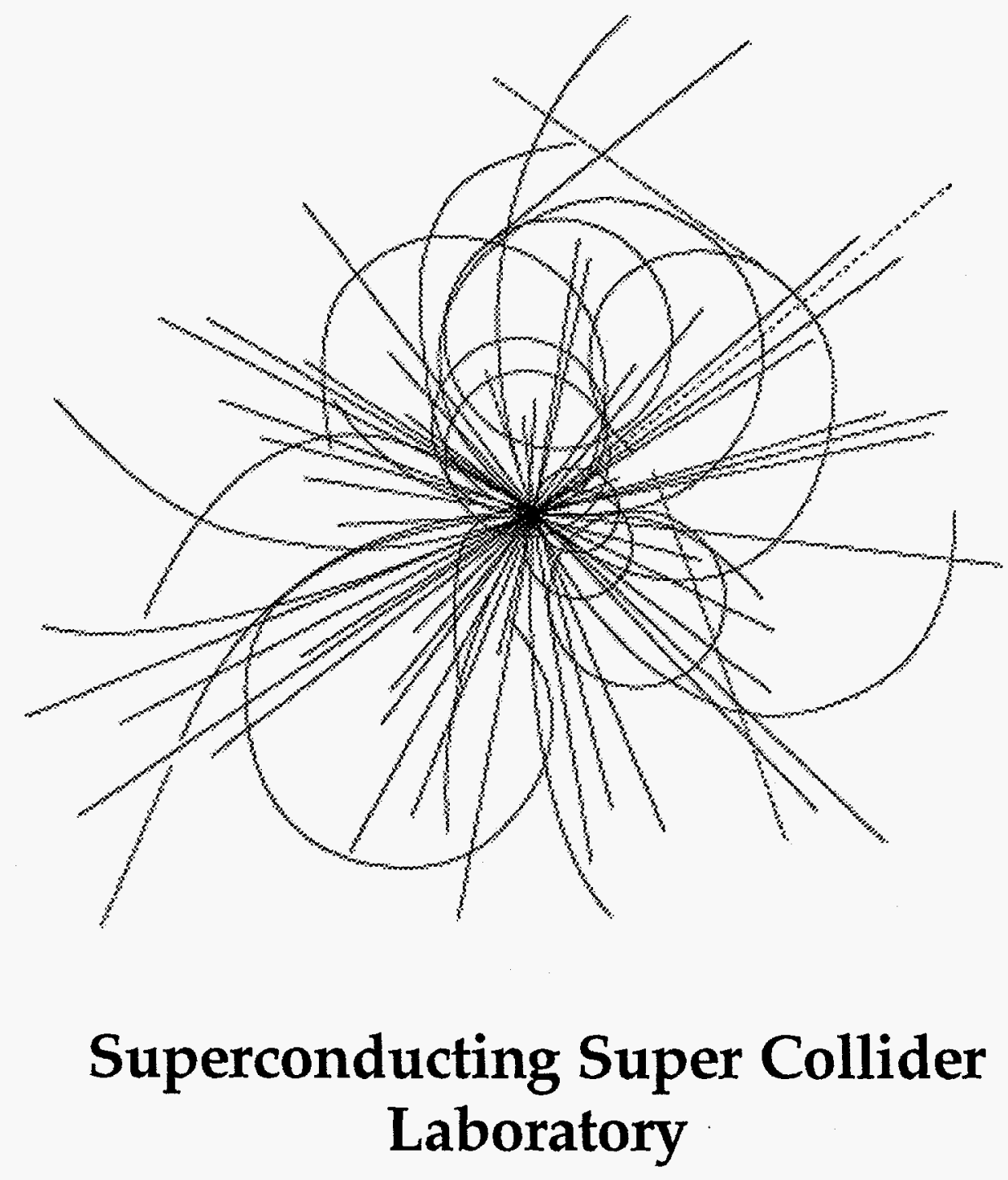

APPROVED FOR RELEASE OR

PUBLICATION - OR. PATENT GROUP

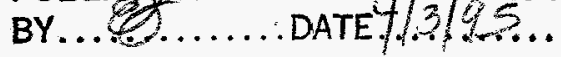




\section{Disclaimer Notice}

This report was prepared as an account of work sponsored by an agency of the United States Government. Neither the United States Government or any agency thereof, nor any of their employees, makes any warranty, express or implied, or assumes any legal liability or responsibility for the accuracy, completeness, or usefulness of any information, apparatus, product, or process disclosed, or represents that its use would not infringe privately owned rights. Reference herein to any specific commercial product, process, or service by trade name, trademark, manufacturer, or otherwise, does not necessarily constitute or imply its endorsement, recommendation, or favoring by the United States Government or any agency thereof. The views and opinions of authors expressed herein do not necessarily state or reflect those of the United States Government or any agency thereot.

Superconducting Super Collider Laboratory is an equal opportunity employer. 


\section{DISCLAIMER}

Portions of this document may be illegible in electronic image products. Images are produced from the best available original document. 
SSCL-670

\title{
Above-Cutoff Impedance Measurements of Pumping Holes for the Collider Liner
}

\author{
L. Walling, T. Barts, E. Ruiz, W. Turner, and N. Spayd
}

\author{
Superconducting Super Collider Laboratory* \\ 2550 Beckleymeade Ave. \\ Dallas, TX 75237 USA
}

April 1994

\section{DISCLAIMER}

This report was prepared as an account of work sponsored by an agency of the United States Government. Neither the United States Government nor any agency thereof, nor any of their employees, makes any warranty, express or implied, or assumes any legal liability or responsibility for the accuracy, completeness, or usefulness of any information, apparatus, product, or process disclosed, or represents that its use would not infringe privately owned rights. Reference herein to any specific commercial product, process, or service by trade name, trademark, manufacturer, or otherwise does not necessarily constitute or imply its endorsement, recommendation, or favoring by the United States Government or any agency thereof. The views and opinions of authors expressed herein do not necessarily state or reflect those of the United States Government or any agency thereof.

* Operated by the Universities Research Association, Inc., for the U.S. Department of Energy under Contract No. DE-AC35-89ER40486. 


\subsection{INTRODUCTION}

A holed liner was considered for the Superconducting Super Collider (SSC) Collider Ring because of vacuum problems caused by photon-induced desorption. The liner would serve to shield the cold surface of the beam tube from the synchrotron radiation and the holes (or slots) would allow distributed pumping by gas-absorption material that could be placed between the liner and the beam tube. The impedance of holes and slots in a liner were studied ${ }^{1,2}$ by means of simulations using both MAFIA and HFSS, analytical modelling, wire measurements and electron beam measurements.

All of these approaches (except the electron beam measurements which did not yield any useful results due to a higher measurement noise level than the impedance signal level) were in extremely good agreement below beampipe cutoff frequency. However, there was disagreement between theory, MAFIA and HFSS for very high frequency (above $15 \mathrm{GHz}$ ). MAFIA showed a rolling off of the reactive impedance at high frequency, whereas nothing in Gluckstern's calculations indicated this, and HFSS simulations did not show this effect. Further, MAFIA calculations showed that the roll-off frequency became lower as the hole size increased (see Figure 1). Therefore we decided to attempt to measure the above-cutoff impedance. It is not possible to measure very small impedances above cutoff using the wire method because both means of error correction that are commonly used in beam impedance measurements require single-mode propagation. Any mode conversion above cutoff would cause difficulty in data analysis which has the practical consequence of reducing the measurement sensitivity. Therefore we decided to adopt the TM01 method developed by Lambertson, Jacob, Rimmer and Voelker. ${ }^{3,4}$

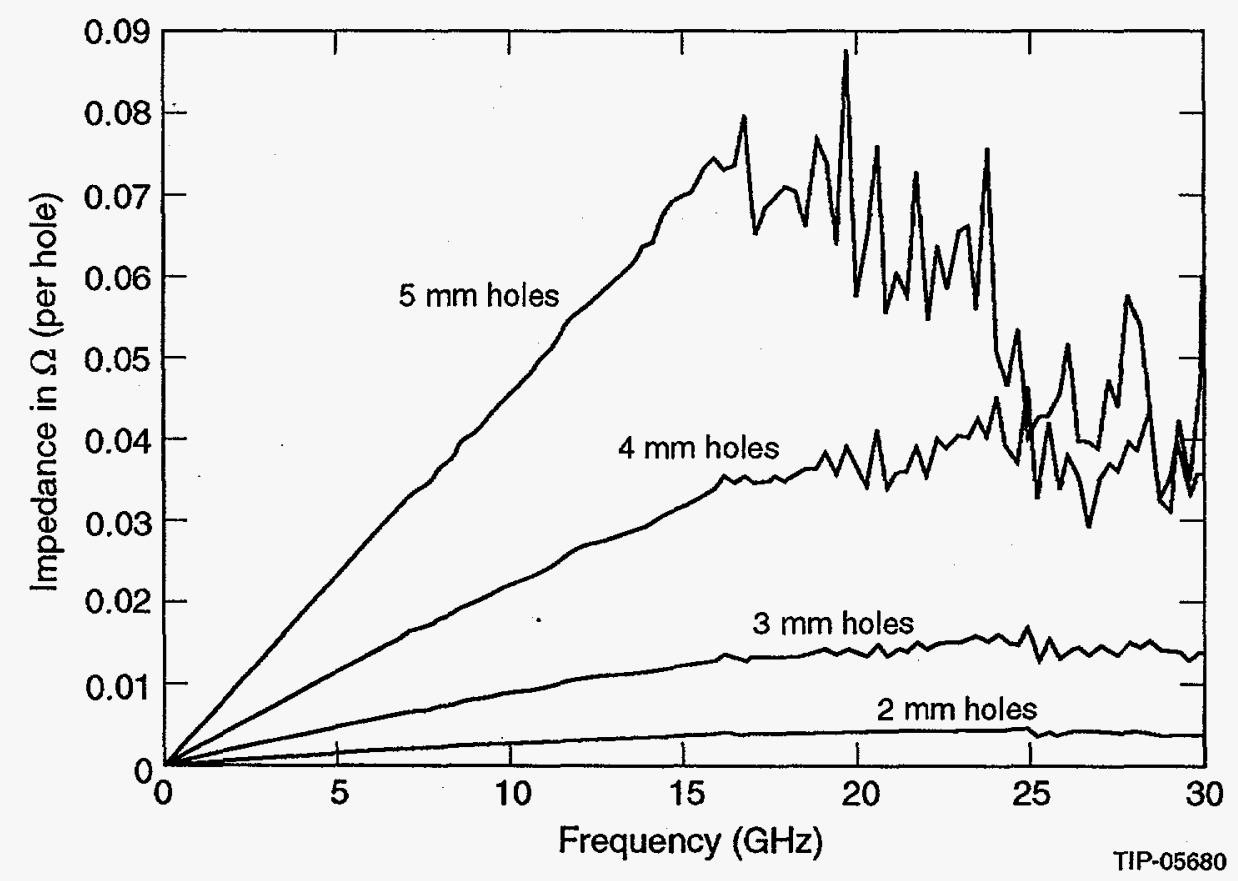

Figure 1. MAFIA Run Results Showing Impedance per Hole for Various Hole Sizes (Beam Pipe Diameter is $33 \mathbf{m m}$.) 


\subsection{DESCRIPTION OF MEASUREMENT METHOD}

The wall currents in tube supporting TMOn propagation are similar to the image current of a beam. Thus, the voltage developed by some perturbation in the beam tube wall would be be related to the beam impedance by $V=I Z_{b}$. As shown in Reference 3, the measurement technique and analysis are analogous to that of the wire measurement, with the TEM line impedance replaced by the wave impedance $Z_{l}$, where

$$
Z_{l}=\frac{Z_{0}}{4 \pi} \sqrt{1-\left(\frac{f_{c}}{f}\right)^{2}}
$$

where $f_{\mathrm{c}}$ is the cutoff frequency of the TM01 mode and $Z_{0}$ is the free space impedance. Thus the line impedance is approximately $30 \Omega$, which is considerably lower than for typical wire measurements (a TEM line formed with a small center conductor is usually 150-200 $\Omega$ or so), which has the agreeable effect of high measurement sensitivity.

This method is only good to the extent that the impedance to be measured is truly excited by a single TMOn mode. Thus the challenge is to provide a wave launcher that produces as pure a TM01 mode as possible (it obviously wouldn't make much sense to attempt the measurement with higher-order modes, since it would be very difficult to suppress the lowest mode).

To accomplish this we first started with the TM01 launcher designed and tested by Lambertson, et al., modeled it using HFSS to study the degree of mode isolation and absorption of higher-order modes, then used HFSS to increase its selectivity (maximally launch TM01 and maximally suppress TM02 and TM03). Acting upon a suggestion from G. Spalek of LANL, we moved the launching edge to the radial electric field node of the TM02 mode to maximally suppress it (since this would be the dominant troublesome mode), then did perturbational modifications of the pieces of absorptive material until we found the best performance. Besides looking at selectivity of launched modes (and thus reconverted modes on the receiver end), we also optimized on absorption of TM02 and TM03 modes, since this condition is necessary to model the energy radiated in traveling waves above cutoff which is created by the mode conversion caused by the impedance being measured. Figure 2 shows a cross section including dimensions of the final design. Figure 3 shows the measured response through a pair of launchers connected by $2 \mathrm{~m}$ of stainless steel pipe (inner radius $16.5 \mathrm{~mm}$ ). The response shows about a $10 \mathrm{~dB}$ improvement over the original launchers. 


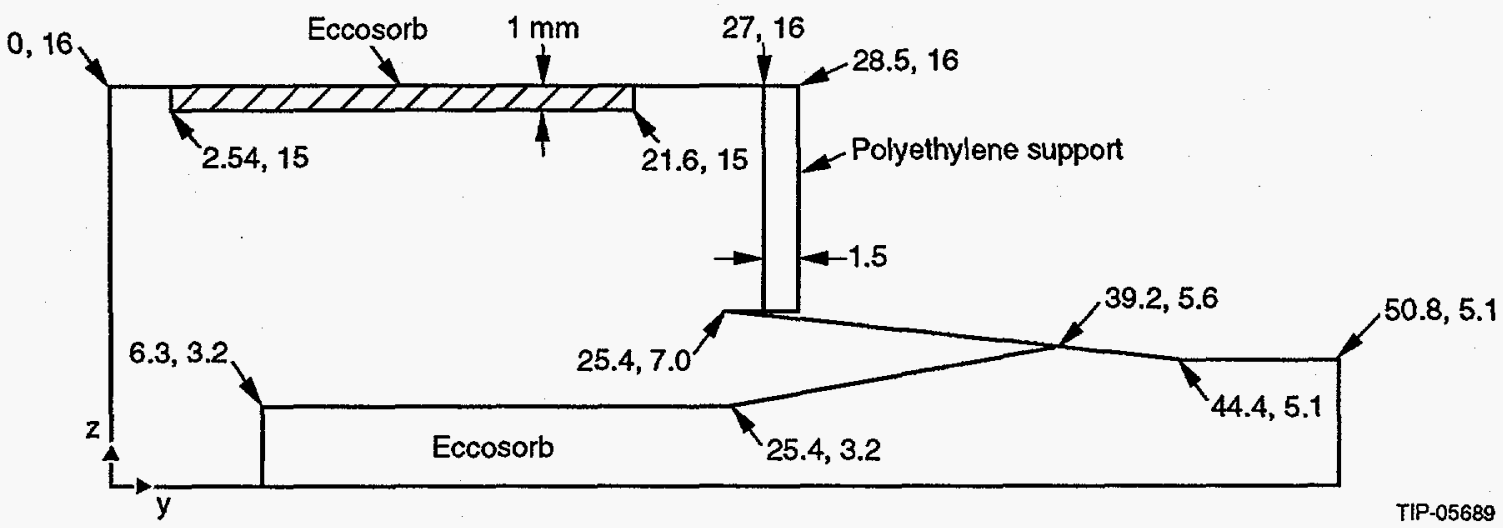

Figure 2. HFSS Model of Launcher Showing Dimensions.

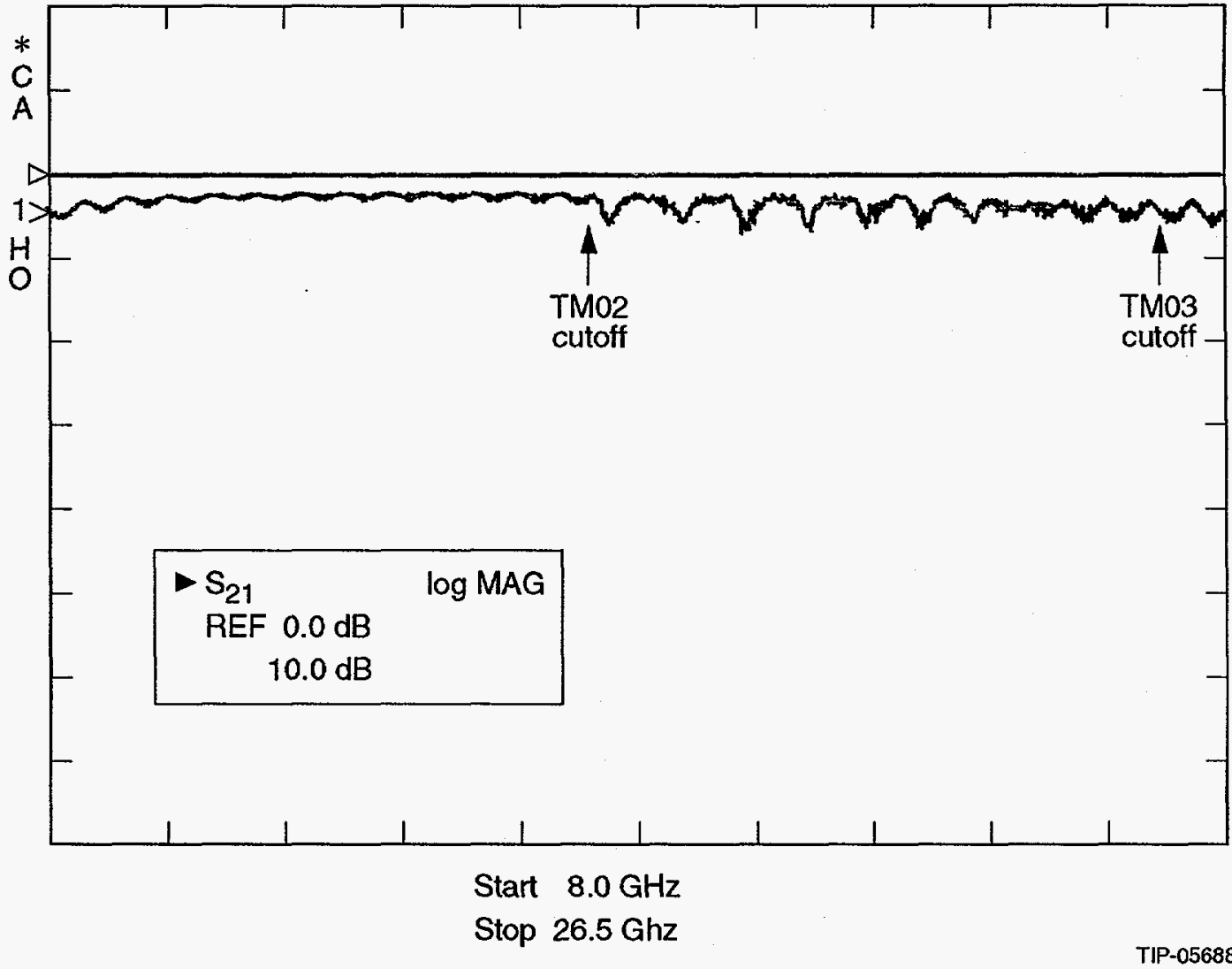

Figure 3. Measured Transmission of Two Launchers Connected by $2 \mathbf{m}$ of Stainless Steel Pipe (Inner Radius 16 mm). 


\subsection{MEASUREMENTS RESULTS}

\subsection{Measurement of Old Pipes with 1010 Holes}

Initially, we decided to measure pipes that we had previously measured by the wire method. We measured three pipes that were about $2 \mathrm{~m}$ in length, and sized to within $+/-40 \mu \mathrm{m}$. The inner diameter of the beam pipe was $33 \mathrm{~mm}$. One pipe was a solid (reference pipe), the others had $10103-\mathrm{mm}$ holes and 1010 4-mm holes, respectively. The measurement results are shown in Figures 4 and 5, with MAFIA results for a similar configuration. The pipes had 101 rows of holes with 10 holes per cross section; the MAFIA runs were of 101 rows of holes with 4 holes per cross section because it is impossible to define 10 holes per cross section with MAFIA's cartesian mesh. To compensate for the number of holes in each cross section, the size of the holes in the MAFIA run were increased by 1.36 (the cube root of 10/4) since the impedance per hole theoretically increases by the cube of the diameter. The different hole size may account for the resonances being at different frequencies than the measurements. Clearly there is a very large discrepancy between the measured and calculated impedances for these measurements. We felt that a likely reason for this discrepancy could be that the TM01 method assumes that any wall impedance would be excited by a pure TM01 mode, and in the case of 101 planes of holes, there is probably significant mode conversion occurring at each hole, causing the holes at successive planes to be excited by a mixture of modes, thus violating the measurement's fundamental assumption. In order to test this further, we decided to measure a pipe with only one plane of holes.

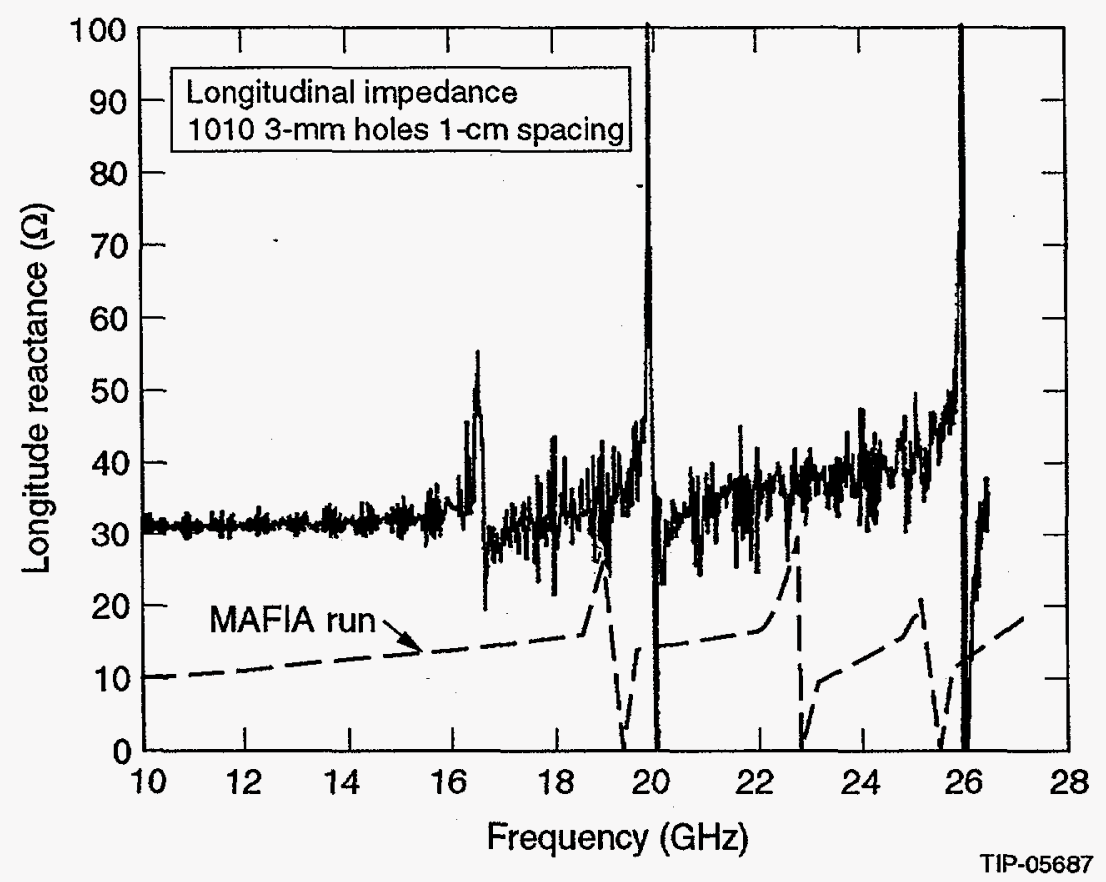

Figure 4. Measurement Results of 1010 3-mm Holes with MAFIA Results Added. 


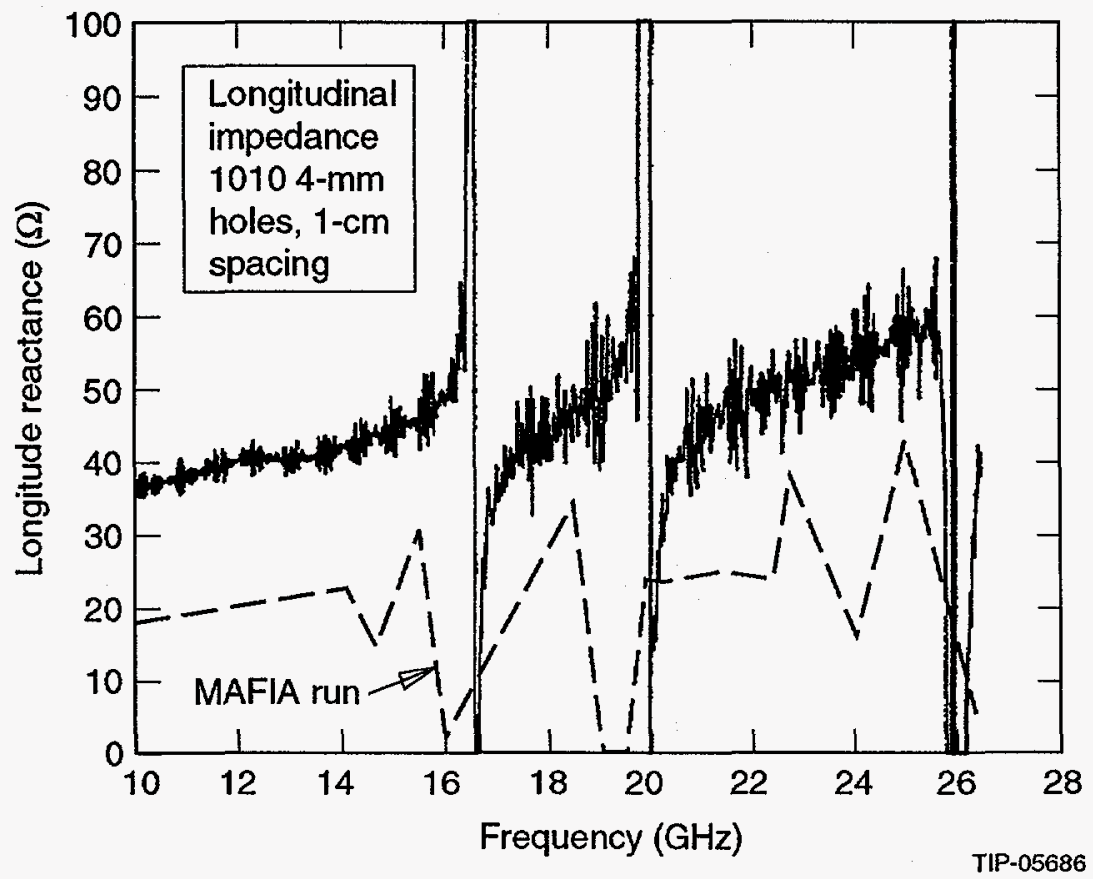

Figure 5. Measurement Results of 1010 4-mm Holes with MAFIA Results Added.

\subsection{Measurement of New Pipes with Four Holes in One Plane}

Luckily, we had'two pipes that had earlier been manufactured and sized to lengths equal within $25 \mu \mathrm{m}$. After studying the noise floors of the measurement, we decided that four 9-mm holes should be measureable with a reasonable signal-to-noise ratio. Before drilling the holes, we decided to measure the transmission of both pipes to check that they were the same length electrically within the expected error. We found a big surprise-we found that the pipes had a fairly constant phase difference of $14.2^{\circ}$ (Figure 6$)$ over the frequency band of interest $(8-26 \mathrm{GHz})$. We do not have a reasonable explanation for a linear phase shift--a difference in mechanical length should provide a phase shift proportional to frequency. However, we decided to proceed and cut the holes in pipe $\# 2$ and measure, applying the $14.2^{\circ}$ phase shift to the normalized data. Figure 7 shows the impedance of the four 9-mm holes, with holes in pipe \#2 referenced to pipe \#1 with $14.2^{\circ}$ phase shift added. The measurement was done two ways - one with the exterior of the holes taped over with conductive-adhesive copper tape, the other with the outer beam pipe installed and eccosorb material placed in the end regions between the liner and beam pipe to absorb any power coupled through the holes.

Because we had some distrust of using a reference pipe with a fixed phase shift, we decided to check it with one more measurement. We measured pipe \#2 during a period of time when the temperature in the laboratory was very stable, then rushed the pipe to the shop where four more 9 -mm holes were cut in a period of about 20 minutes, then re-measured the same pipe as soon as the temperature of the pipe stabilized (there was some heating due to the machining). Figure 8 shows the impedance measured with the test pipe referenced to itself without the holes. Figure 9 is the same as Figure 8, except that time-gating has been applied to clean up the data, and the MAFIA results for four $9-\mathrm{mm}$ holes have been drawn on the plot. This data shows agreement between 
MAFIA and the measurements for the resonances at about $16 \mathrm{GHz}$ and $22 \mathrm{GHz}$, but below $14 \mathrm{GHz}$ there is disagreement with MAFIA, with MAFIA values 30-50\% lower. Analytical calculations would be closer to the measured values (Figure 10 shows the MAFIA results with the analytical curve shown), however it may be that the analytical calculation breaks down for holes this large. The shapes of the resonances look difference because of the low-resolution of the MAFIA runs.

(a)

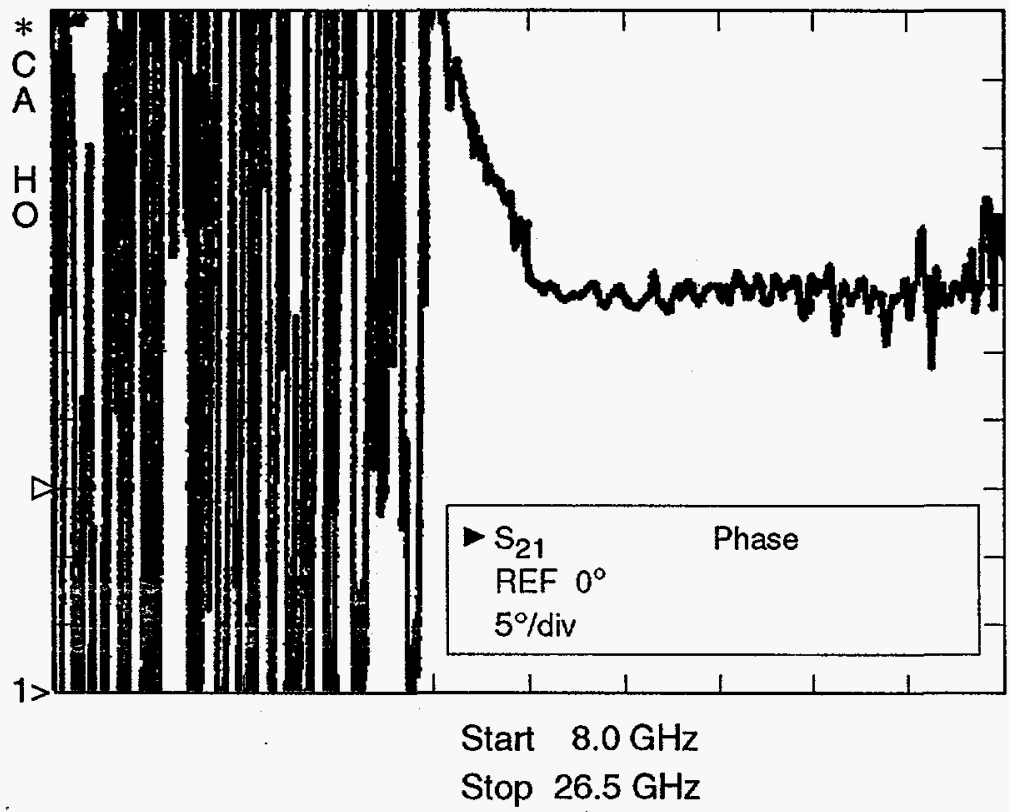

(b)

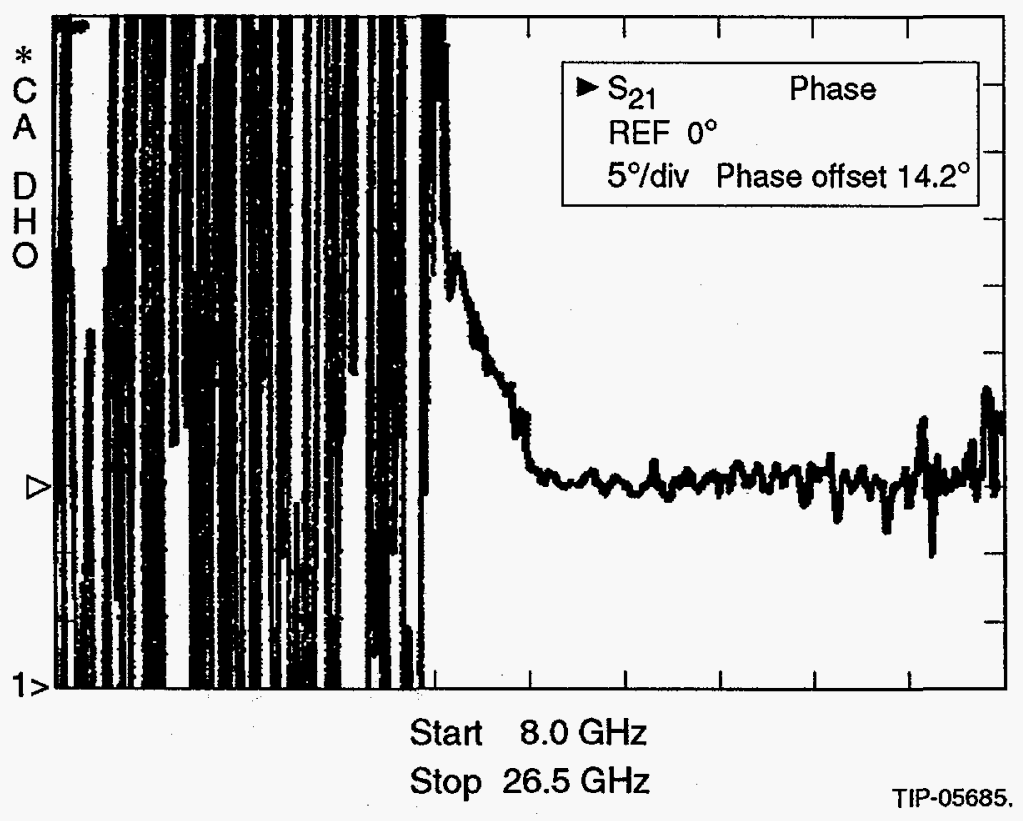

Figure 6. Transmission Phase of Pipe \#2 Referenced to Pipe \#2. 
(a)

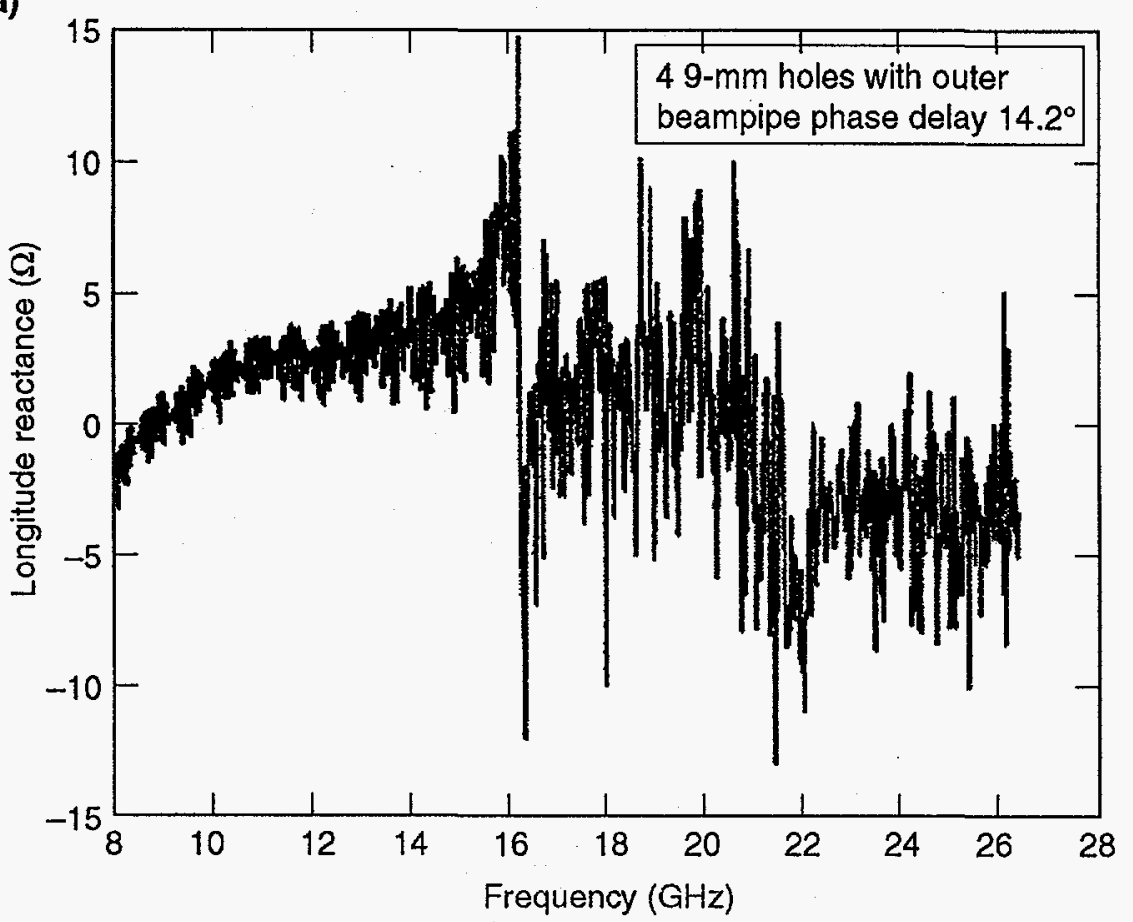

(b)

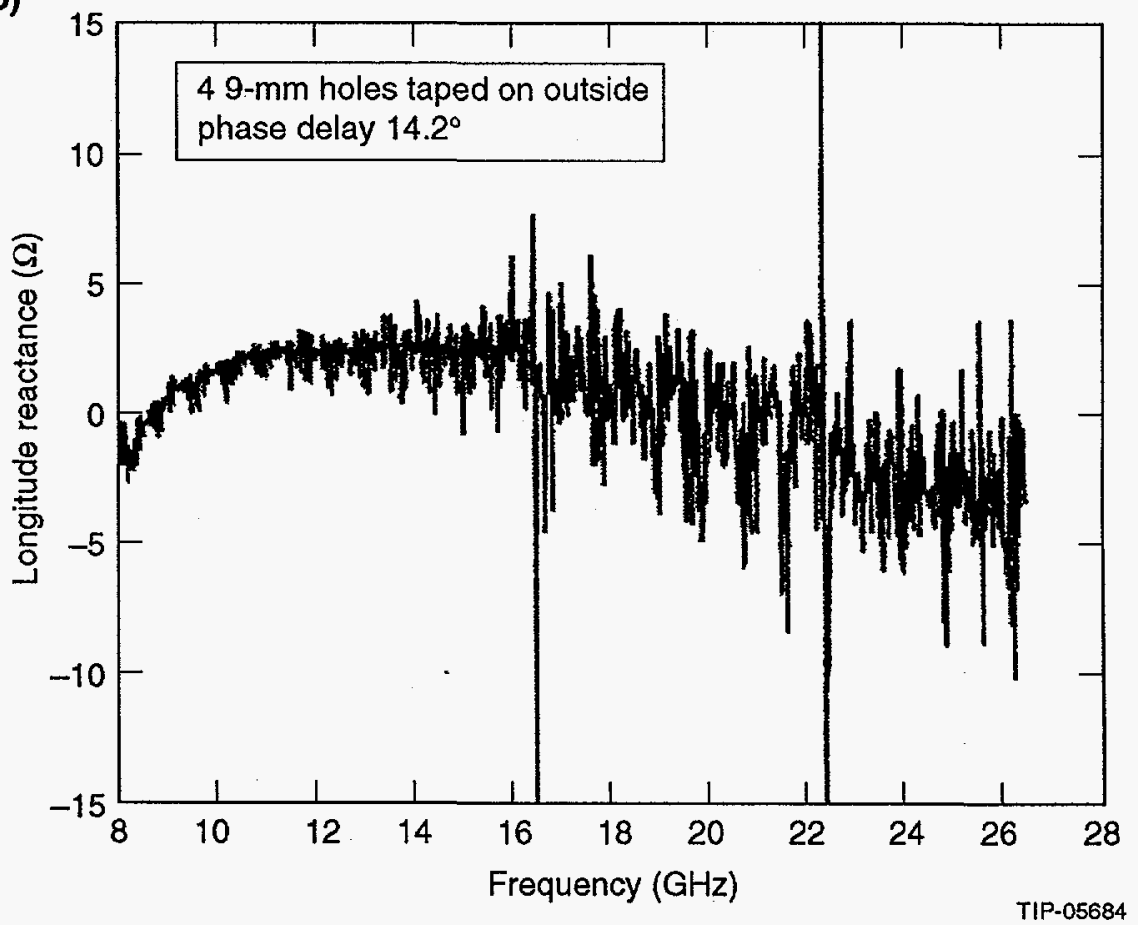

Figure 7. Measurement Results for 9-mm Holes Applying Phase Offset of $14.2^{\circ}$ to Compensate for Electrical Length Difference Between Test and Reference Pipe. Top figure is for the liner with beampipe; bottom one is for beampipe removed and exterior of holes taped with copper tape with conductive adhesive. 
(a)
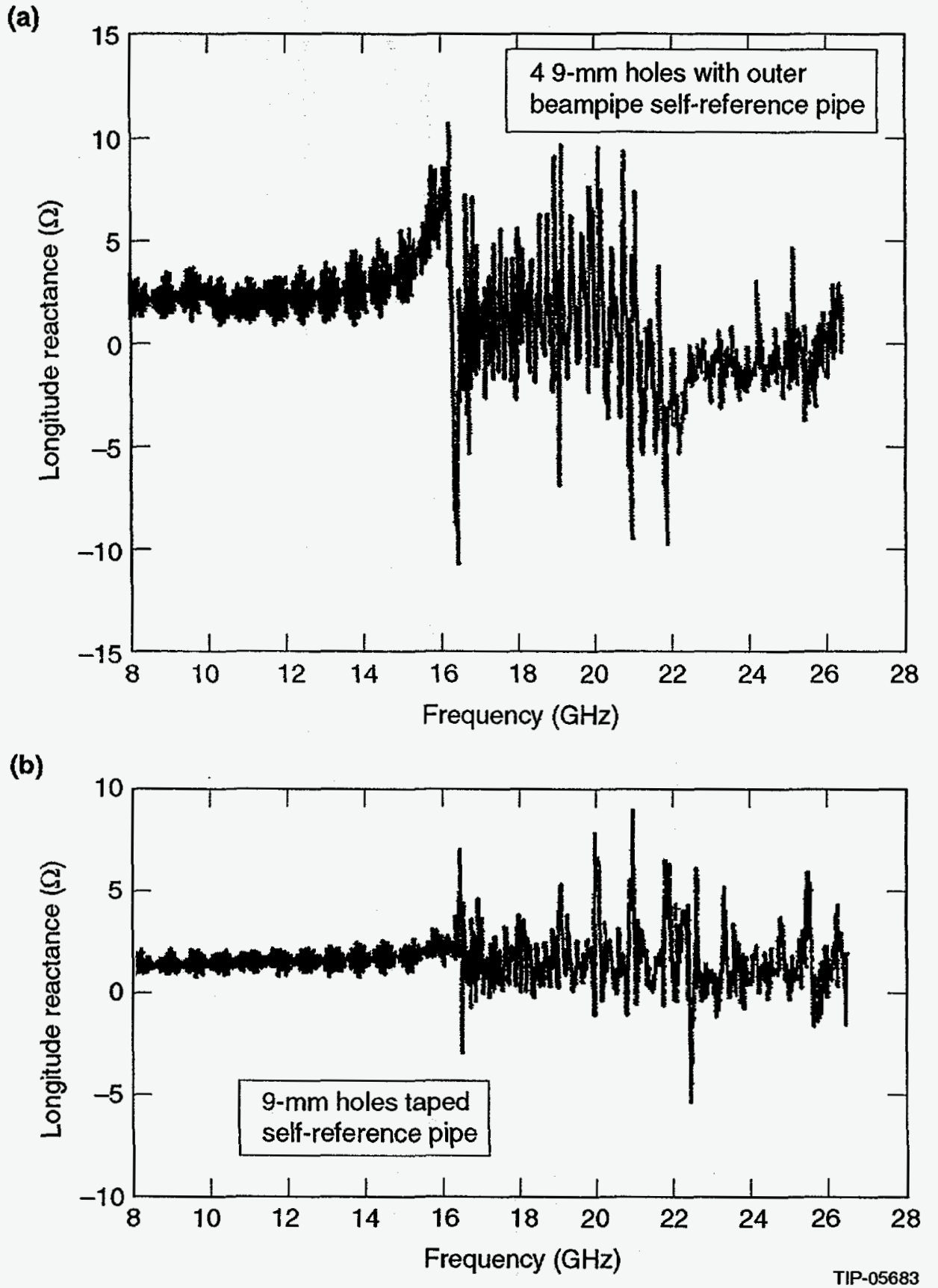

Figure 8. Measurement Results for 9-mm Holes Using the Same Pipe for Reference and Test. Top figure is for the liner with beampipe; bottom one is for beampipe removed and exterior of holes taped with copper tape with conductive adhesive. 


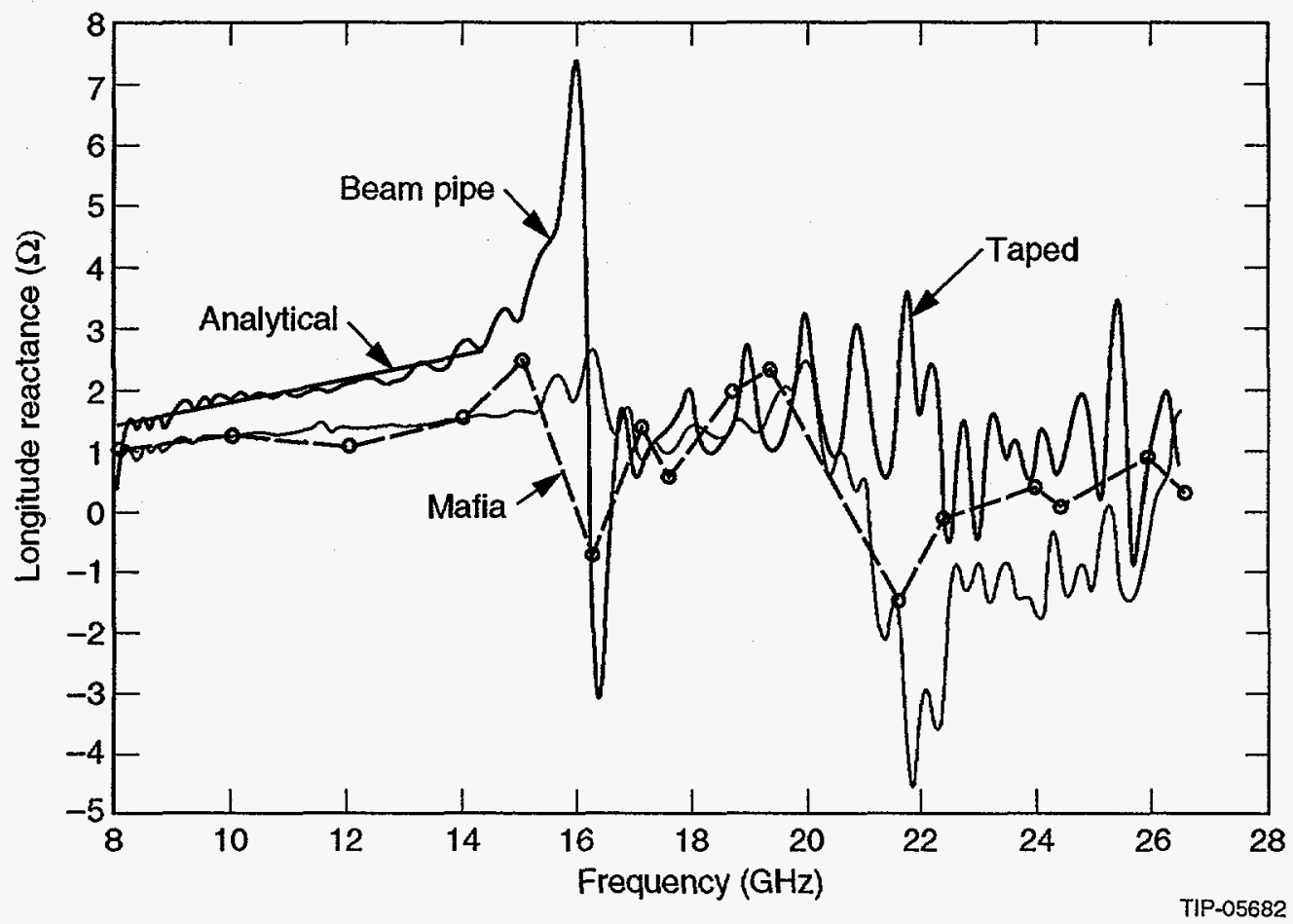

Figure 9. Measurement Results for 9-mm Holes Using the Same Pipe for Reference and Test with Time-gating Applied to Smooth Out Noise of Measurement and MAFIA Results Added.

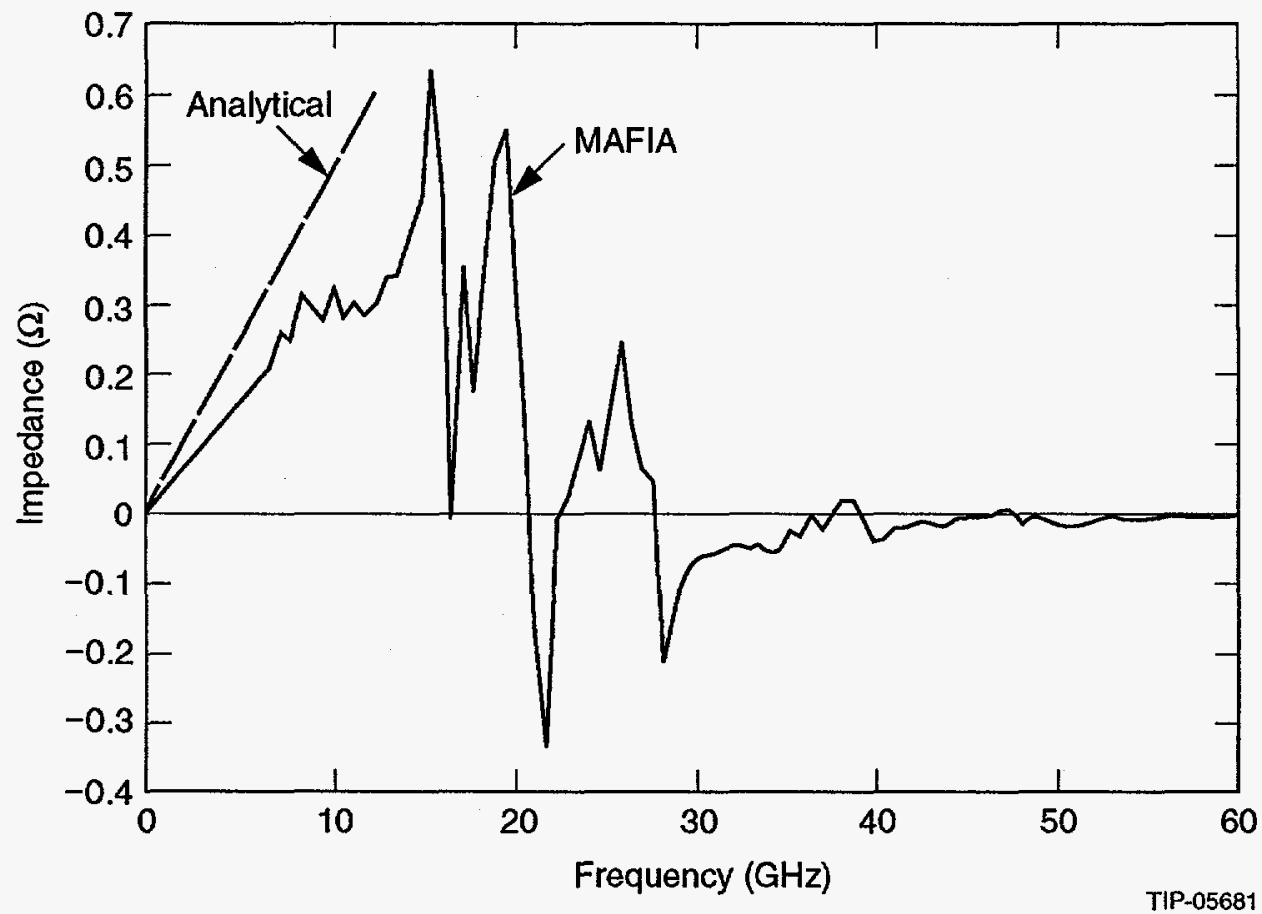

Figure 10. MAFIA Results for four 9-mm Holes with Analytical Curve Added. 


\subsection{CONCLUSIONS}

Although this work is by no means conclusive in either confirming the high-frequency behavior of holes in a beam pipe, or in establishing the degree of usefulness of the TM01 method is measuring beam impedances, we feel we have established that there is reason to believe that (1) the MAFIA calculations are correct in that the impedance of the holes does roll off at high frequency instead of increasingly linearly with frequency and (2) the TM01 method is useful for studying above-cutoff impedance for disturbances that are localized along the axis. The measurements performed with the old pipes with 1010 holes do not yield much information, since we later learned that having two pipes of the same mechanical length does not guarantee a sound reference pipe electrically for the TM01 method. Therefore we wish to disregard this data. However, the measurements of the 9 -mm holes, where, first, corrections based on electrical measurements of the two pipes (before holes were cut) were performed, and secondly, measurements were done using one pipe for both reference and test, yield data that we deem reliable enough to give some validity to both the results and the method.

\section{ACKNOWLEDGMENTS}

The author thanks CTS for graciously allowing Therese Barts to use MAFIA during SSC's postmortem period. 


\section{REFERENCES}

1. "Transmission-Line Impedance Measurements for an Advanced Hadron Facility," L. S. Walling, D. E. McMurry, D. V. Neuffer, and H. A. Thiessen, Nucl. Instr. and Meth. A281 (1989) 433.

2. "Design Report on the SSCL Prototype 80 K Synchrotron Radiation Liner System," T. Barts, W. Chou, et al., SSCL-SR-1224, September 1993.

3. "Techniques for Beam Impedance Measurements Above Cutoff," G. Lambertson, A. Jacob, R. Rimmer, F. Voelker, Proc. of European Particle Accel. Conf., Nice, France, 1990.

4. "Beam Impedance Measurements on the ALS Curved Sector Tank," R. Rimmer, D. Goldberg, A. Jacob, G. Lambertson, F. Voelker, Proc. of European Particle Accel. Conf., Nice, France, 1990. 